Conference Report

\title{
Spiritual Care Education of Health Care Professionals
}

\section{Donia Baldacchino ${ }^{1,2,3}$}

1 Faculty of Health Sciences, University of Malta, Msida MSD 2090, Malta; E-Mail: donia.baldacchino@um.edu.mt; Tel: +356-2340-1847

2 Department of Nursing, University of South Wales, Pontypridd Rhondda Cynon Taff CF37 4BE, Wales, UK

3 Department of Nursing, Johns Hopkins University, Baltimore, MD 21218, USA

Academic Editors: Arndt Büssing and Hefti René

Received: 2 February 2015 / Accepted: 16 April 2015 / Published: 8 May 2015

\begin{abstract}
Nurses and health care professionals should have an active role in meeting the spiritual needs of patients in collaboration with the family and the chaplain. Literature criticizes the impaired holistic care because the spiritual dimension is often overlooked by health care professionals. This could be due to feelings of incompetence due to lack of education on spiritual care; lack of inter-professional education (IPE); work overload; lack of time; different cultures; lack of attention to personal spirituality; ethical issues and unwillingness to deliver spiritual care. Literature defines spiritual care as recognizing, respecting, and meeting patients' spiritual needs; facilitating participation in religious rituals; communicating through listening and talking with clients; being with the patient by caring, supporting, and showing empathy; promoting a sense of well-being by helping them to find meaning and purpose in their illness and overall life; and referring them to other professionals, including the chaplain/pastor. This paper outlines the systematic mode of intra-professional theoretical education on spiritual care and its integration into their clinical practice; supported by role modeling. Examples will be given from the author's creative and innovative ways of teaching spiritual care to undergraduate and post-graduate students. The essence of spiritual care is being in doing whereby personal spirituality and therapeutic use of self contribute towards effective holistic care. While taking into consideration the factors that may inhibit and enhance the delivery of spiritual care, recommendations are proposed to the education, clinical, and management sectors for further research and personal spirituality to ameliorate patient holistic care.
\end{abstract}


Keywords: spiritual care; holistic care; education; Benner's Theory; Kolb's Theory; ASSET model; role modeling; students; health care professionals; intra/inter-professional education

\section{Introduction}

The International Council of Nurses (ICN) Code of Ethics ([1], p. 5) specifies the nurse's role of promoting "an environment in which the human rights, values, customs and spiritual beliefs of the individual, family and community are respected". The Malta Code of Ethics supports this for nurses and midwives [2], stating that the nurse is to "recognize and respect the uniqueness of every patient/client's biological, psychological, social and spiritual status and needs". Since patients are attended by different members of the multi-disciplinary team, these codes of ethics also address the holistic care of health care professionals that contribute towards patients' safety. Examples of some heroes in nursing are given, whereby, their being in care generated signs of spirituality in their attempts to address patients' needs, while their caring attitude instilled hope and healing.

Nightingale [3] proposed that the environment should do no harm to patients. In this paper, the environment is provided by the presence of nurses and health care professionals, including the ward management personnel who attempt to deliver care holistically. Patients' safety may be achieved by individualized spiritual care, whereby care is given according to the patients' biological, psychological, social, cultural, and spiritual needs [4]. Mary Seacole (1805-1881) nursed sick soldiers in the Crimean War so kindly that she was known as "Mother Seacole". Mary was exposed to prejudice and racism, as her mother was from the Caribbean island of Jamaica and her father was Scottish. However, courageously, Mary made her own way in the world, as a single woman and as a person of mixed race. Mary mixed medicine with kindness and thus she is an admired role model to nurses and health caregivers [5]. Elisabeth Cadwa-ladyr from Wales volunteered to nurse sick soldiers in the Crimean War with Florence Nightingale in 1854. Betsy was devoutly religious and the small Welsh Bible, given to her when she was young, remained her "constant companion" and appeared to help her overcome the disappointments of her distorted plans in life and accept her situation in life [6].

During the last twenty-five years, care of patients has been criticized for neglecting the spiritual dimension in patient care [7]. This may be due to various reasons such as, secularization of contemporary society, unwillingness to deliver spiritual care, lack of time, work overload, feelings of incompetence to deliver spiritual care, lack of education in undergraduate and post-graduate curricula, and lack of inter-professional education, which generate omission of spiritual care [8-10]. Additionally, the medical model addresses primarily the illness of the patient and its progress to cure, while overlooking the religious and spiritual needs, and, consequently, threatens holistic care.

\section{Definition of Spirituality in Illness}

Spirituality is derived from the Latin word spiritus; spirit is the important part of the person that controls the mind, and the mind controls the body [11]. Religion may shed light on the interpretation of this spirit. For example, as a Roman Catholic person, I relate this spirit to the spirit of God within me, which gives me life day by day. Spirituality is also the power within a person that motivates that 
person to find meaning, purpose, and fulfillment in life; suffering and death; and fosters hope for one's will to live [12]. It infers that spirituality is the vital life force that unifies all aspects of the human being, including the religious component [13].

However, spirituality goes beyond religious affiliation, as it strives for inspirations, meaning and purpose in life, even in those who do not believe in any god/higher power [14,15]. Consequently, spirituality applies to both believers and non-believers, including the presence of different cultural and religious beliefs. Thus, when a person is more in tune with the vital, unifying, life force of the spiritual dimension, a will gain a more balanced state of physical, mental and social well-being, as a result [16].

\section{Definition of Spiritual Care}

Spiritual care is part of the art of nursing and professional care [17]. Spiritual care is defined by the literature as recognizing, respecting, and meeting patients' spiritual needs; facilitating participation in religious rituals; communicating through listening and talking with clients; being with the patient by caring, supporting, and showing empathy; promoting a sense of well-being by helping them to find meaning and purpose in their illness and overall life; and referring them to other professionals, including chaplains/pastors [18]. The outcome of spiritual care was found to enable patients to count their blessings in life, achieve inner peace and explore coping strategies to overcome obstacles during illness and crisis situations [19-21]. Spiritual care may also help patients to find a new equilibrium in faith by re-conceptualizing the self as one who is known and loved by God in the context of their specific illness [22,23].

The essence of spiritual care is being rather than simply doing [24]. Thus, therapeutic use of self is of utmost importance [25]. The role of the multidisciplinary team is to help patients find meaning in illness and purpose in life with a positive outlook to life and/or afterlife. Thus, in spiritual care it is not merely the delivery of care that matters, but it also includes the heart and the spirit by which holistic care is given [26].

In order to address spiritual needs both in health and in illness, competences are needed to guide the education of the health care professionals.

\section{Aim}

The aim of this paper is to present the theories and methods of clinical education on spiritual care of health care professionals and students, and outline the dimensions of spiritual leadership to sustain the learning process.

\section{Competences in Spiritual Care}

The Nursing and Midwifery Council (NMC) in the UK [27] in line with the European Qualifications Framework (EQF) [28] defines competence as "the proven ability to use knowledge, skills and personal, social and/or methodological abilities in the work or study situations and in professional and personal development" ([28], p. 11) referred to as "responsibility and autonomy" ([28], p. 11).

Benner's Theory "From Novice to Expert" [29] defined nursing competency as the ability to perform a task with desirable outcomes under the varied circumstances of the real world. Benner 
placed competence in the middle of the continuum ranging from: novice to advanced beginner, to competent, to proficient, to expert. Competent practitioners are consciously able to plan their actions, but lack flexibility and speed [30]. The practitioner is described as "tolerably good but less than expert" because when practitioners are considered competent, they would still have something more to achieve for them to reach the level of proficiency and expertise [31]. This is highly applicable to the education of health care professionals. While considering the characteristics of the students who are undertaking the nursing, medical and paramedical education programs, who are young, with a lack of personal life experiences and with minimum attention to spiritual issues in life, it is very important not only to equip students with loads of information, but also attention needs to be given to their personal formation as spiritual individuals, who find meaning and purpose in their profession, and to help them develop the necessary skills and attitudes across their education programs in class and in the clinical practice. This process will contribute towards transformation into a professional health care being who becomes responsible and accountable for holistic patient care including the spiritual dimension of care.

Students and health care professionals need to achieve competence, i.e., acquiring knowledge, skills and attitudes. Spiritual care competence is defined as an active ongoing process characterized by three interrelated elements which involve a growing awareness of one's value, developing an empathic understanding of the client's world view and the ability to implement individualized interventions appropriate to each client [32].

Research on competences in spiritual care is growing. An exploratory study in Malta that collected qualitative data from nurses, hospital and community chaplains as well as patients with heart attack revealed the following seven generic competences: integrating the individual person within the role of the nurse as a professional; assisting the search for meaning of illness and acceptance of illness; maintaining trustful relationship with patients and family; communicating with patients, inter-disciplinary team and clinical/educational Organizations; delivering spiritual care by the four stages of the nursing process that is, assessment, planning, implementation and evaluation; controlling ethical issues in care such as, confidentiality, data protection issues; and delivering holistic care [33].

These findings supported the three core themes derived from an extensive literature review which revealed three core domains of competences for spiritual care namely, awareness and use of self; spiritual dimensions of the nursing process (assessment, planning, implementation and evaluation of care); and assurance and quality expertise [34].

Research has shown that the strongest predictor for effective spiritual care is personal spirituality. No one can give from what he/she does not possess. This indicates the importance of maintaining the integrity between the individual person and the role of health care professionals to address and meet patients' needs holistically [35]. Therefore, health care professionals can both provide spiritual care and can also provide care spiritually [36]. Since, competence in professional practice incorporates knowledge, skills and attitudes with achievable outcomes [37], additional to knowledge, the active presence of the health care professional, that is being in doing, not simply doing, is needed to meet patients' spiritual needs and to generate the holistic doing of spiritual care. Therefore, the therapeutic use of self could be very helpful as it may enhance a trustful helping relationship.

Research recommends that health care professionals should take an active role in meeting patients' spiritual needs and not simply refer them to a chaplain [38]. However, it is argued that when patients need help in their theological beliefs and conflicts, then the chaplain, an expert with Clinical Pastoral 
Education should deliver this kind of specialized spiritual care [39]. Hence, the importance of considering the hospital chaplain/pastor as an important collaborator in the inter-disciplinary team [40], especially when prepared educationally for a chaplain's role [41].

While considering the importance of the responsibility of the health care professionals, research shows the concern of the nurses and health care professionals who consider themselves as incompetent to deliver spiritual care [42].

\section{Education on Spiritual Care/Modes of Clinical Education on Spiritual Care}

An overview of the theoretical and practical education on spiritual care is included based on a literature review following a literature search using the keywords: "spiritual care", "holistic care", “education”, “Benner's Theory”, “Kolb's Theory”, “ASSET model”, "role modelling”, "students”, "nurses", "health care professionals", and "intra/inter-professional education". Additionally, the author's teaching experience in Malta and in various foreign universities presented some examples of innovative teaching methods adopted to teach spirituality and spiritual care to undergraduate and post-graduate students. Spiritual care contributes towards holistic care, which demands a multi-disciplinary team approach to care, including the chaplain. This may be enhanced by intra- and inter-professional education on spiritual care as it may foster teamwork and team learning.

\subsection{Intra-Professional and/or Inter-Professional Education on Spiritual Care}

Intra-professional education is when students from different levels of education in the same profession are taught together. For example, currently, at the Faculty of Health Sciences in Malta, final year nursing students work in their clinical placements with first year students under the same mentor in preparation for the formative and summative clinical assessment. Feedback from both the first and final year students is generally very satisfactory and the intra-professional clinical experience is considered a rich learning opportunity. This experience supports project results in clinical simulation, which support intra-professional nursing student education [43].

Inter-professional education (IPE) is also known as multi-professional education, common learning, shared learning, and interdisciplinary learning [44]. Therefore, inter-professional education refers to students from different professions learning from each other, with each other, and about each other. The WHO-Study Group, consisting of 30 education, practice and policy experts, issued the WHO Framework for Action on Inter-professional Education and collaborative Practice [45]. The framework highlights:

- The current status of inter-professional collaboration around the world; identifies the mechanisms that shape successful collaborative teamwork; outlines a series of action items that policy makers can apply within their local health system; and

- Provides strategies and ideas that can help health policymakers implement the elements of inter-professional education and collaborative practice that will be most beneficial in their own jurisdiction.

The effectiveness of inter-professional education in enabling collaborative practice is still debatable. Some evidence was found by research studies on, for example 'death and dying learning' [46], and systematic reviews [47], and on the effectiveness in changing attitudes [48]. However, more 
longitudinal research is needed to identify the possible effects on service quality and patients' and service users' experiences.

Inter-professional education (IPE) was also implemented to teach different professions, such as social workers and chaplains; also IPE was adopted on students from different professions such as medicine, nursing, chaplaincy and social work [49]. Online learning and interactive simulation modes of teaching were adopted. Educational programs on spiritual and cultural aspects of palliative care and spiritual assessment demonstrated that concepts of spirituality and basics of spiritual assessment may be taught and learned while students were found to develop an understanding and respect for the role of chaplains, social workers and physicians. Evaluation of these programs suggests that this innovative, inter-professional educational course may be transferable for use in other educational settings [50]. In addition to the physical presence of students together in class, online forums enable learners to discuss and outline the contribution of each discipline to spiritual care and holistic care of a patient case study. Thus, online forums may enhance understanding and appreciation of the precious contribution of each member of the interdisciplinary team to holistic care.

\subsection{Areas Essential for Learning Spiritual Care}

A literature review identified four main areas as essential for learning spiritual care:

a. importance of learning in real-life situations with repeated exposure to patients in the clinical placements supported by role modeling and mentorship;

b. use of pedagogical methods that assist students to understand, work with and reflect on patient's spirituality such as, reflective journals, written reflective accounts; writing care plans, which include spiritual interventions; role plays to practice spiritual assessment, including values, beliefs, and spiritual needs; group discussions on the relationship between religion, spirituality and health; analysis of case studies; reading literature and analyzing research on spirituality in illness and care;

c. awareness of and overcoming conditions inhibiting spiritual care learning, such as, lack of knowledge about spirituality; uncertainty about the health care professional's role in spiritual care; unawareness about one's own spirituality; having a different faith from that of the patient; incompetence in addressing spiritual needs; lack of role models; lack of time; and work overload; and

d. evaluation of students' spiritual care learning related to how students are prepared and how they are followed up after clinical studies by, for example, post clinical-reflection sessions; sharing of stories with fellow students, teachers and chaplains; supporting their learning by literature and research on spiritual care; reflective exercises and debriefing sessions to enhance safety of students and safe patient care' [51].

These are reflected in the ASSET Model for (Actioning Spirituality and Spiritual Care Education and Training) for teaching spiritual care [52].

The ASSET model incorporates a tripod of structure content, process of learning and outcome of education. First, the structure content encompasses self-awareness, spirituality and spiritual dimensions of care. Second, the process of teaching and learning incorporates experiential learning related to value 
clarification, holism, a broad perspective of spirituality, the four stages of the nursing process, and evaluation of teaching and learning. Third, the outcome of education, which is measured by value clarification, knowledge and competence in the delivery of spiritual care.

The foundation of this model lies on the importance of nurses' self-awareness about their personal spiritual beliefs, communication skills, and assessment procedures. Spirituality in this model has a Judeo-Christian perspective. However, it is argued that the present era of displaced individuals and refugees with different religions demands inclusion of other religions. Culture and interdisciplinary teamwork including the chaplain play an important role in this model.

Culture may challenge both the students and the educator. In summer 2013 and 2014, I was invited to teach various groups of students undertaking undergraduate courses such as nursing, psychology and tourism; and post-graduate students undertaking counseling, pastoral care, theology, and psychology programs at two Pontifical Catholic Universities in Parana` Brazil. Following analysis of the definition of the concept of spirituality to a group of forty five students undertaking BA Psychology, a student asked me, "What has motivated you to tackle spirituality and spiritual care?" Having a class of young students in a quite secularized class environment, I explained my personal spirituality regarding what gives me meaning and purpose in my life. This was oriented towards my Catholic religious background, my affiliation with the Society of Christian Education, and my clinical experience in Intensive Care Unit (ITU), and also my clinical care of an Arabic patient in a British hospital whose prayers calmed him down post-operatively [53]. At the end of the session, several young students shared with me privately their religious and/or their spiritual experiences in life. These sessions appeared to stimulate ten students, (six were aged 19-22 years; four were mature, over 23 years), to attend also the research group session because they wished to investigate spirituality in their research project.

Culture was again prominent in my teaching visit at the University of Pardubice, Czech Republic in 2014. It was interesting to note that a paramedic male student, aged 20 years asked me the same question! "What motivated you to tackle spirituality and spiritual care?" Having referred to my research findings on Maltese patients' spiritual coping strategies, of which some were religious coping, students with an atheistic background asked me "Who is God? What is the relationship between God's plans in life and 'destiny' and 'coincidence' in life?" These profound questions generated discussions across the whole week of my stay at the university.

Therefore, education of health care professionals should prepare students to recognize and act on spiritual cues; and build a trusting relationship and communicate respectfully and sensitively to patients to discover what is important to patients. Education should focus on holistic patient care with attention to spiritual and existential themes throughout the nursing program to help students integrate learning into the clinical practice [54].

Research could also be a medium of learning to explore the real experiences of patients and a resource of learning on spirituality in illness and care. Thus, the author tried to give the opportunity to patients with acute and chronic illness and healthcare professionals, consisting of hospital/community chaplains and qualified nurses working in medical and surgical wards, to participate in various research studies. While giving voice to patients and health care professionals, they contributed additional knowledge on the importance of spirituality and culture in care $[55,56]$. 


\subsection{Integrating Theoretical Learning on Spiritual Care into the Clinical Practice}

Literature review on how to develop a clinical learning culture emphasizes the importance of role model attitudes and behaviors of the health care professionals [57]. Role modeling in spiritual care is a concept that is still theoretical in nature because of various reasons, such as feelings of incompetence to deliver spiritual care and secularization of the contemporary society. It is argued that spiritual care may be "caught rather than taught" [58]. However, research shows that both theoretical teaching and clinical practice are needed in the education on spiritual care $[59,60]$. The clinical environment fosters integration of knowledge, clinical reasoning and formation of students [61]. Practice facilitates students' discovery of professional beliefs, values and attitudes and it assists them in integrating relevant knowledge and theories [62].

Experiential learning and voluntary work could also be a resource of learning for health care professionals [63]. As presented earlier on the inter-professional educational programs, core study units and organization of short- or long-term voluntary activities facilitate students from various disciplines to learn together and share their learning experiences. Optional study units at the University of Malta are open to all university students. However, timetables may clash with other study units rendering a limited mix of students.

Voluntary work may play an important role in students' learning in the form of community outreach. Voluntary work is acknowledged by the University of Malta DegreePlus. Thus, a study unit of 2 European Credits Transfer System (ECTS) on Spiritual Care for Health Caregivers (NUR3903) offers the students to do a minimum of five hours voluntary care in the community or accompany patients on a pilgrimage, such as to Lourdes in France. The experience of a group of seven students consisting of four nursing and three midwifery students was impressive! It was a means of self-reflection with enhancement of altruism. They confirmed the principle of giving and receiving as they were impressed by the patients' religious faith to travel so far to a sacred place, with an outcome of empowerment to cope with their illness [64].

Voluntary work also took the format of a health promotion activity to groups of adults, mostly older persons in the community by a small group of three to five undergraduate nursing students. The program consisted of students' delivery of a 20-minute Power Point presentation on preventive measures and care of diabetes or hypertension; and they answered the queries of the audience under the author's supervision or a parish nurse. The audience themselves were then asked to teach the group of students, by stating and interpreting proverbs or life principles of which spirituality was prominent. Finally, the blood pressure was measured by students on voluntary basis. Following the community outreach session, all students (average of 20 students) sit around and share their experiences using Gibb's Theory of Reflection [65]. Finally, a written reflective account formed part of the study unit assessment strategy where students reflected on such an inter-generational teaching and learning experience, which was usually a very positive experience.

This learning experience may take the format of a small group of three to four nursing students paying a visit to a family taking care of a person with terminal illness at home; or visiting an older person living alone at home while being supported by a relative/neighbor as an informal caregiver and/or community service. Such a learning experience on how the patient and family coped in their 
past and current life by the use of various religious and/or spiritual coping methods was usually interpreted by students as "an experience which I will treasure for life".

These health promotion activities in the community were further extended to students' participation on a one-hour weekly radio program: Il-Kuragg nofs il-Fejqan (Courage doubles the healing process) on Radio Maria in Malta. A small group of three to four nursing students delivered a teaching session on health promotion in my presence and the author responded live to the public queries on telephone and text messages. This experience helped them to confirm the nurse's educational role in the community.

\subsection{The Use of Arts in Identifying the Spiritual Dimension of the Role of the Nurse in Holistic Care}

Towards the end of the introductory study units (NUR0118/NUR1116) for first year nursing students on foundations in nursing, they were invited to identify the spiritual dimension of the role of the nurse in providing holistic care by drawing their thoughts on a piece of white paper. A brief explanation was written by students on the back of the picture. This arts exercise helped them to explain and analyze the complexity of the spiritual dimension in holistic care. After three years that is, at the end of their nursing course program, a focus group of 12 nursing students discussed the differences they noticed between the perceived version and the observed real-life holistic care. This exercise enabled students to identify the preciousness and inaccuracies in the observed delivery of holistic care and the importance of addressing patients' spiritual needs to facilitate holistic care.

An experiential learning was conducted on first year students in their clinical placement with institutionalized older persons. Only few clients from each ward attend the activity center, leaving the majority of older persons passive, sitting all day, waiting for their meals to be served and perhaps waiting for someone to visit and communicate with them. On paying a visit to these students under the author's link-mentorship, students were found at the nurses' station discussing together the patients' documented care, which was also a learning resource for them. However, students could not understand the possible feelings of boredom and isolation experienced by older persons every day, day in day out, until they could pass through this experience.

Permission was granted by the respective hospital and ward administration and following individual's written consent, a group of fifteen first year nursing students were invited to experience an hour of aloneness, segregated in a room alone for an hour on the same day without having the wall clock. Using Kolb's Theory of experiential learning [66], each student stayed alone in a deserted room on their respective ward, coordinated by their respective mentor and the author. Each student was asked to enter the room without the uniform clock and without her/his mobile phone. During that hour, students were asked to reflect on their experience and write notes on a piece of paper. The majority of students experienced boredom due to lack of time orientation and communication system. They became frustrated as that hour was eternity for them. The common exclamation of students on coming out of that room was: "how boring! Poor them!" During the follow-up focus group discussion, this experience was applied to the older persons' aloneness on the ward and confirmed the importance of communication and activity exercises to help them live with dignity. Thus, transfer of knowledge appeared to be facilitated by this experiential learning session. A written reflective account of their critical experience was submitted as part of their clinical portfolio and followed up by counseling as deemed necessary. 
The ability to be present is crucial in spiritual care. Availability, concentration at work and reflection allow students to bear witness to patients' suffering and do something meaningfully about it without getting immune to patient's suffering. Ability to listen to unspoken words accompanied by compassion and sensitivity is part of professional presence and spiritual care. Thus, the nurses' and health care professionals' connection and rapport with patients are fundamental for spiritual care [67]. Assignment of a mentor in the clinical environment fosters individual follow up system on a one-to-one basis to help students to identify spirituality as part of the fabric of everyday patient care. This also demands good collaboration between students, lecturers, health care professionals, and clinical mentors for optimal learning outcomes. Furthermore, leadership in the clinical environment plays a key role in maintaining holistic and creating a good learning environment [68].

\subsection{Creating a Clinical Environment Conducive to Learning Spiritual Care}

The Personal spirituality of the caregiver was found by research as the strongest predictor for perceiving ability to provide spiritual care as no one can give from what he/she does not possess [69,70]. Personal spirituality enables caregivers to be sensitive to patients' cultural and spiritual needs in their holistic care [71-73]. Hence, the importance for students to be helped to reflect and explore their own spirituality as it allows students to be more sensitive to the spirituality of others [74-76]. Research shows that students reported discomfort with self-reflection, but it provided them with access to their own growth [77].

Since health care professionals form the major part of the clinical environment of patients, attention needs to be given to the spiritual dimension and the holistic perspective of the health care professionals at the workplace $[78,79]$. Personal spirituality refers to an attitude and/or a lifestyle of an individual, which recognizes his/her own spiritual dimension of one's life. When personal spirituality is acknowledged, teamwork will generate a peaceful environment with enhanced patient care, incorporating also the individual patients' spirituality in their care. Implementation of spirituality in the clinical and the academic environments may motivate health care professionals to search meaning and purpose in their work, understand the value of work and become aware of their personal belief system [80]. The education system both in the clinical and the faculty sectors need highly motivated educators who radiate happiness and peacefulness to others, including students, colleagues and patients [81]. To sustain such an environment conducive to learning and self-development, the managers need to link their personal life values and educators' values to the respective university values, which may eventually pass on these values to students resulting in spiritual growth of both students and educators $[82,83]$.

Literature suggests that a successful learning environment is created through inspirational leadership, reflective management and creation of a positive partnership between the clinical setting and the educational organization [84-87].

The spiritual leadership theory was adopted as a guide for such an inspirational leadership in the education of spiritual care. This is based on an intrinsic motivation model and on characteristics such as, faith, hope and altruism, which may generate homogeneous vision and values at the individual, team, and organizational levels [88]. These values may eventually generate higher levels of commitment to holistic care supported by spiritual leadership [89]. 
Fry identifies seven dimensions of spiritual leadership that may be applied to an environment conducive to learning, which are vision, altruistic love, hope/faith, membership, meaning/calling, organizational commitment and productivity.

Vision: As a result of the advancement of technology, patient care may be enhanced but at the same time health care professionals may be distracted from the actual holistic care of the person under their care [90]. The vision looks to the future goal to be reached, which gives meaning to the organization's aspirations, and fosters hope and faith [91]. Ideally, undergraduates and post-graduate learners need to be grouped together and learn together in classrooms and clinical seminar rooms about holistic care of specific patients. Methods of education are consistently changing such as, the introduction of online course programs that may facilitate interdisciplinary education.

Altruism: is a set of values, of going beyond one's needs to deliver care to others, and ways of thinking that are morally right, and are shared by group members and taught to new members. These values may be taught theoretically, but also by role models, during patient care and communication with colleagues.

Hope/Faith: During this pathway of looking to the future, hope and faith in the ability of the educators and the students themselves may help actualization of the set vision and goals to be achieved successfully in the proposed mission. The individuals' spiritual belief system may generate empowerment along this pathway.

Membership: The diversity of religious affiliations, spiritual beliefs, culture and social structures, demands efforts to try to understand each other and appreciate each other's strengths and tolerate each other's limitations with the intention to generate self-development and team work. This collegial process stems from the interactions and communication between the members of the multidisciplinary team and also the development of therapeutic relationship with the patient $[92,93]$.

Meaning/Calling: Educators in the faculty and clinical placements identify the "calling"/vocational aspect as the sacred part of the profession, which may yield a transcendent experience, while becoming aware of the related empowerment to dedicate oneself to the care of others professionally. Eventually, educators may realize the worth of serving others, the wealth of making a difference in students' and patients' lives. Hopefully, through reflection, educators may realize that while they are giving to others, they are also receiving. Consequently, meaning and purpose in life is created along the pathway of learning from each other. Thus, the actual work environment is transformed into a workplace with a social meaning and value and not simply a job of people, or just seeking competence and knowledge [94].

Organizational Commitment: The practice of altruism, safe belongingness, and a sense of meaning at work will contribute towards a healthy environment, enhanced collegiality and collaboration, with less stress-induced sick leave, higher motivation and faithfulness to their individual "calling"/vocation in their respective profession. Thus an environment with a culture based on values and altruism may generate role-models to teach spiritual care and feelings of peace and security at work [95].

Productivity: Productivity is interpreted as an intelligent process of implementing interventions based on research evidence, creativity and innovations to achieve the set goals. Consistent reflection in and on action may lessen mistakes in care, one of which is the neglect of the spiritual dimension in care [96]. 
These characteristics may foster learning by role models generated from an environment of cooperation, trust, commitment and effectiveness of collegial work [97]. This environment may be inhibited by various factors, such as work overload, lack of time, incomplete staff complement, lack of job security [98], impaired personal spirituality, and career motivation system [99]. Motivation supported by personal spirituality was found positively related with better performance due to achievement of goals at work and collegial relationship in the education and delivery of holistic care [100].

\section{Conclusions}

Research identifies the active role of the nurses and health care professionals in meeting the spiritual needs of patients in collaboration with the family and the chaplain. However, it is well documented that nurses and health care professionals have overlooked the spiritual dimension in care with the consequence of threatening holistic care. While considering the complexity of spirituality and spiritual care, and the barriers to the delivery of spiritual care documented in the literature, the author presented various innovative teaching methods, which were introduced in various undergraduate and post-graduate course programs of nurses and health care professionals in Malta and foreign universities. The teaching methods integrated within the theoretical and clinical dimensions were guided by conceptual models to enhance learning such as, Benner's theory: From Novice to Expert: Excellence and Power in Clinical Nursing Practice; Kolb's experiential learning theory; Gibbs theory of reflective learning; and the ASSET model for Actioning Spirituality and Spiritual care Education and Training in nursing. Experiential learning, visits in the community, reflective exercises and reflective written accounts, use of arts for expression of the complex concepts of spiritual care, discussions on observed delivery of holistic care, participation in research, tutorials, and role modeling were identified as beneficial resources of learning. Various factors were identified which may influence students' education on spiritual care, such as characteristics of students, the extent to which the academic and clinical environments in hospital and in community are conducive to learning, and culture. This paper identifies the essence of spiritual care, which is being in doing, whereby personal spirituality and therapeutic use of self may contribute towards the education and delivery of spiritual care and holistic care.

\section{Recommendations}

The following recommendations are set for the education, clinical, and management sectors; personal spirituality; and further research to enhance education on spiritual care.

\subsection{Education}

Students tend to be examination-oriented so they tend to prefer to study for their examinations. Thus, examining clinical skills in spiritual care would identify the degree of acquisition of competence in spiritual care. Therefore, a framework on competences in spiritual care needs to be developed as a guide for the education and clinical sectors.

Literature confirmed that theoretical study units on spiritual care may be effective to the nurses' and midwives' perceived competence in spiritual care. Continuous professional development (CPD) is 
mandatory by reading literature and research, attending seminars, conferences, CPD courses on spiritual care in order to achieve competence and maintain high quality holistic care [101-103].

\subsection{Clinical Practice}

Literature discusses spiritual care learning as part of a total curriculum program emphasizing the clinical studies and ways of facilitating reflection in practice together with clinical tutorials as important in the students' learning process. Thus, students need to be provided with 'teachable moments" by reflecting with students on patient care so that they can learn and approach new encounters with greater awareness and appropriate action [104].

Clinical practice presents students with diverse and rich opportunities to learn about the reality and nature of patients' spiritual needs and spiritual well-being in real-life situations. Students need to practice before they can fully understand the theoretical component. Thus role-modeling by health care professionals and mentors in the clinical placements is of utmost importance to help students to understand and to implement spiritual care. Furthermore, an effective dialogue between the clinical settings and the educational organizations is needed to maximize learning opportunities for students.

Spirituality and spiritual care are complex concepts, especially when faced with the diverse religions held by patients in hospital and the community. Learning about the relationship between religion and health care is of utmost importance especially in this era of immigrants with different religious affiliations who are admitted to hospital. Additionally, addressing spiritual distress and spiritual needs may involve various ethical issues, such as confidentiality in documenting certain aspects of spiritual assessment. Thus, support groups are needed for debriefing sessions to express feelings, biases and address ethical issues involved in spiritual care.

\subsection{Management}

Spiritual leadership is needed to develop a clinical environment conducive to learning spiritual care by facilitating holistic care and teamwork, which foster spirituality at the workplace.

Awareness of the sacredness of the caring profession and clinical environment is essential.

"When comparing the hospital to a sanctuary, the patient is the tabernacle", whereby the patient is the center of holistic care [105].

\subsection{Further Research}

Further transcultural longitudinal research is needed to identify the most appropriate and effective pedagogical approaches to teach spiritual care to students [106], such as by online and interactive simulation by intra-professional and inter-professional educational programs.

\subsection{Personal Spirituality}

The frequency of attending religious services and spiritual experiences were found to contribute towards the students' positive attitude towards spiritual care [107]. Thus, further research is suggested to identify the possible impact of personal characteristics, such as age, gender, personality traits, religious practices and life experiences on holistic care. 
Personal religiosity and spirituality of students, their mentors and health care professionals may foster a healthy spiritual clinical environment. Thus, organization of spiritual retreats, prayer meetings for students and health care professionals may be beneficial to both the caregiver and the recipient of their care. Finally, the richness of both the theoretical presentations and socio-religious events during the European Conference on Religion Spirituality and Health in Malta in 2014, may enhance motivation to become change agents with the possible ultimate ripple beneficial effects of spiritual care:

If you reform your spiritual-self, you will reform your professional care;

If you reform your professional care, you will reform your holistic care;

If you reform your holistic care, you will reform the care spiritually.

\section{Acknowledgments}

The author appreciates the cooperation of Roberta Sammut, Head of the Nursing Department, Faculty of Health Sciences; the hospitals'/residences' managers; the Catholic church authorities of the day centers in the community; the Caritas and related Agencies; the Scientific Committee of the ECRSH 2014 Conference; the nursing students who undertook the study units related to spiritual care; Lilian Bonello for proof reading; Family Attard for providing a quiet reflective seaside environment to write this manuscript; and the three anonymous reviewers.

\section{Conflicts of Interest}

The author declares no conflict of interest.

\section{References}

1. International Council for Nurses (ICN). Code of Ethics for Nurses. Geneva: ICN, 2000.

2. Nursing and Midwifery Board. Maltese Code of Ethics for Nurses and Midwives. Valletta: Nursing and Midwifery Board, 2001.

3. Florence Nightingale. Notes on Nursing: What Is Nursing and What Is Not. New York: Dover Publications Inc., 1860.

4. Donia Baldacchino. Spirituality in Illness and Care. Blata 1-Bajda: Preca Library, 2003.

5. BBC. "Why Is Mary Seacole Famous? The History of Mary Seacole." 2015. Available online: http://www.bbc.co.uk/schools/primaryhistory/famouspeople/mary_seacole/ (accessed on 30 March 2014).

6. Jane Williams. Betsy Cadwaladyr: A Balaclave Nurse. An Autobiography of Elisabeth Davis. Dinas Powys: Dinefwr Press, 2007.

7. Wilfred McSherry, and Linda Ross. Spiritual Assessment in Healthcare Practice. Cumbria: M \& K Update Ltd., 2010.

8. Wendy Cadge, Elaine Howard Ecklund, and Nicholas Short. "Religion and Spirituality: A barrier and a bridge in everyday professional work of Paediatric Physicians." Journal of Social Problems 56 (2009): 702-21. 
9. Susan Ronaldson, Lilian Hayes, Christina Aggar, Jennifer Green, and Michele Carey. "Spirituality and Spiritual Caring: Nurses' Perspectives and Practice in Palliative and Acute Care Environments." Journal of Clinical Nursing 21 (2012): 2126-35.

10. Michael J. Balboni, Adam Sullivan, Andrea C. Enzinger, Zachary D. Epstein-Peterson, Yolanda D. Tseng, Christine Mitchell, Joshua Niska, Angelika Zollfrank, Tyler J. Vanderweele, and Tracy A. Balboni. "Nurse and physician barriers to spiritual care provision at end of life." Journal of Pain Symptom Management 48 (2014): 400-10.

11. Betty Neuman. The Neuman Systems Model. Norwalk: Appleton and Lange, 2010.

12. Larry F. Renetzky. "The fourth dimension: Applications to the social services." In Spiritual Well-Being. Sociological Perspectives. Edited by David O. Moberg. New York: University Press of America, 1979.

13. Donia Baldacchino, and Peter Draper. "Spiritual coping strategies: A review of the nursing research literature.” Journal of Advanced Nursing 34 (2001): 833-41.

14. Ruth Murray, and Judith Proctor Zentner. Nursing Concepts for Health Promotion. London: Prentice Hall, 1989.

15. Kristina Torskenes, Donia Baldacchino, Tracey Baldacchino, Josette Borg, Marica Falzon, and Mary Kalfoss. 'Nurses' and informal caregivers' definition of spirituality from the Christian perspective: A comparative study between Malta and Norway." Journal of Nursing Management 23 (2013): 39-53.

16. Carolyn Young, and Cyndie Koopsen. Spirituality, Health, and Healing: An Integrative Approach, 2nd ed. Sudbury: Jones \& Bartlett Learning, 2011.

17. Donia Baldacchino. "Spiritual Care: Is it the nurse's role?" Spirituality \& Health International 9 (2009): 270-84.

18. Linda Ross. Nurses' Perceptions of Spiritual Care. Avebury: Aldershot, 1997.

19. Mohsen Saffari, Harold Koenig, Ghader Ghanizadeh, Amir H. Pakpour, and Donia R. Baldacchino. "Psychometric Properties of the Persian Spiritual Coping Strategies Scale in Haemodialysis Patients." Journal of Religion \& Health 53 (2013): 1025-35.

20. Mohsen Saffari, Amir H. Pakpour, Maryam K. Naderi, Harold Koenig, Donia R. Baldacchino, and Chrystal N. Piper. "Spiritual coping, religiosity and quality of life: A study on Muslim clients on haemodialyis." Nephrology 18 (2013): 269-75.

21. Cynthia Kociszewski. "A Phenomenological pilot study of the nurses' experience providing spiritual care." Journal of Holistic Nursing 21 (2003): 131-48.

22. Leslie van Dover, and Jane Pfeiffe. "Patients of parish nurses experience renewed spiritual identity: A grounded theory study.” Journal of Advanced Nursing 68 (2011): 1824-33.

23. Terry L. Koenig. "Caregivers use of spirituality in ethical decision-making." Journal of Gerentological Social Work 45 (2014): 155-72.

24. Tracy A. Balboni, Mary E. Paulk, Michael J. Balboni, Andrea C. Phelps, Elisabeth T. Loggers, Alexi A. Wright, Susan D. Block, Eldrin F. Lewis, John R. Peteet, and Holly G. Prigerson. "Provision of spiritual care to patients with advanced cancer: Associations with medical care and quality of life near death." Journal of Clinical Oncology 28 (2010): 445-52.

25. Dawn Freshwater. "The Therapeutic Use of Self in Nursing." 2002. Available online: http://www.uk.sagepub.com/upm-data/9470_011394Ch1.pdf (accessed on 5 April 2015). 
26. Ann Bradshaw. Lighting the Lamp. The Spiritual Dimension of Nursing Care. Middlesex: Scutari Press, 1994.

27. The Nursing and Midwifery Council. The Nursing and Midwifery Council (NMC) in the UK Requirements for Pre-Registration Nursing Programme. London: NMC, 2002.

28. The European Qualifications Framework for Lifelong Learning. The European Qualifications Framework for Lifelong Learning. Belgium: European Commission Press, 2008.

29. Patricia Benner. "Issues in competency-based training." Nursing Outlook 30 (1982): 303-09.

30. Patricia Benner. From Novice to Expert: Excellence and Power in Clinical Nursing Practice. Menlo Park: Addison-Wesley, 1984.

31. Michael Eraut. Developing Professional Knowledge and Competence. London: Falmer Press, 1994.

32. David R. Hodge. "Developing cultural competence with Evangelical Christians." Families in Societies 85 (2004): 251-60.

33. Donia Baldacchino. "Nursing competencies for spiritual care." Journal of Clinical Nursing 15 (2006): 885-96.

34. Rene van Leeuwen, and Barth Cusveller. "Nursing competencies for spiritual care." Journal of Advanced Nursing 48 (2004): 234-46.

35. Mikael Lundmark. "Attitudes to spiritual care among nursing staff in a Swedish oncology clinic." Journal of Clinical Nursing 15 (2006): 863-74.

36. Denise Miner-Williams. "Putting a puzzle together: Making spirituality meaningful for nursing using an evolving theoretical framework." Journal of Clinical Nursing 15 (2006): 811-21.

37. William M. Sullivan. "Medicine under threat: Professionalism and professional identity." Canadian Medical Association Journal 162 (2000): 1-7.

38. Josephine Attard, and Donia Baldacchino. "The demand for competencies in Spiritual care in nursing and midwifery education: A literature review." Revista Pistis Praxis, Teologia Pastorale 6 (2014): 671-91.

39. Gowri Anandarajah, and Ellen Hight. "Spirituality and medical practice: Using the HOPE Questions as a practical tool for spiritual assessment." American Family Physician 63 (2001): 81-89.

40. Donia Baldacchino. "The nurse's role in spiritual care: A comparative study between perceptions of patients with first myocardial infarction and health carers in Malta." In Nursing Today. Edited by L. Beldean, U. Zeitler and L. Rogozea. Editura: Alma Mater, 2005, pp. 137-46.

41. Emily M. Cramer, and Kelly E. Tenzek. "The Chaplain profession from the employer perspective: An analysis of hospice chaplain Job Advertisements." Journal of Health Care Chaplaincy 18 (2012): 133-50.

42. Linda Ross, Rene van Leeuwen, Donia Baldacchino, Tove Giske, Wilfred McSherry, Aru Narayanasamy, Carmel Downes, Paul Jarvis, and Annemiek Schep-Akkerman. "Student nurses perceptions of spirituality and competence in delivering spiritual care: A European pilot study." Nurse Education Today 34 (2014): 697-702.

43. Brenda Leonard, Elaine L. H. Shuhaibar, and Ruth Chen. "Nursing student perceptions of intra-professional team education using high-fidelity simulation." Journal of Nursing Education 49 (2010): 628-31. 
44. Centre for the Advancement of Inter-professional Education (CAIPE). Inter-Professional Education-A Definition. London: CAIPE Bulletin, 1997, vol. 13, p.19.

45. Health Professions Networks, Nursing and Midwifery, and Human Resources for Health. Framework for Action on Inter-Professional Education and Collaborative Practice. Geneva: W.H.O. Press, 2010. Available online: http://whqlibdoc.who.int/hq/2010/WHO_HRH_HPN_ 10.3_eng.pdf (accessed on 10 May 2014).

46. Louisa Mcllwaine, Valentine Scarlett, Alan Venters, and Jean Ker. "The different levels of learning about dying and death: An evaluation of a personal, professional and inter-professional learning journey." Medical Teaching 29 (2007): 151-59.

47. Marilyn Hammick, Della Freeth, Ivan Koppel, Scott Reeves, and Hugh Barr. "A best evidence systematic review of inter-professional education: BEME Guide No 9." Medical Teaching 29 (2007): 735-51.

48. Katherine Pollard, and Margaret E. Miers. "From students to professionals: Results of a longitudinal study of attitudes to pre-qualifying collaborative learning and working in health and social care in the United Kingdom.” Journal of Interprofessional Care 22 (2008): 399-416.

49. Robin Lennon-Dearing, Joseph A. Florence, Helen Halvorsin, and James T. Pollard. "An interprofessional educational approach to teaching spiritual assessment." Journal of Healthcare Chaplain 18 (2012): 121-32.

50. Matthew S. Ellman, Dena Schulman-Green, Leslie Blatt, Susan Asher, Diane Viveiros, Joshua Clark, and Margaret Bia. "Using online learning and interactive simulation to teach spiritual and cultural aspects of palliative care to inter-professional students." Journal of Palliative Medicine 15 (2012): 1240-47.

51. Tove Giske. "How undergraduate nursing students learn to care for patients spiritually in clinical studies-A review of literature.” Journal of Nursing Management 20 (2012): 1-9.

52. Aru Narayanasamy. "ASSET: A model for actioning spirituality and spiritual care education and training in nursing." Nurse Education Today 19 (1999): 274-85.

53. Donia Baldacchino. Spiritual Care: Being in Doing. Blata 1-Bajda: Preca Library, 2010.

54. Pamela P. Cone, and Tove Giske. "Teaching spiritual care-A grounded theory study among undergraduate nursing educators." Journal of Clinical Nursing 22 (2012): 1951-60.

55. Donia Baldacchino. "Spiritual Care Education of Health Care Professionals." Available online: www.ecrsh.eu/mm/Baldacchino_-_Keynote_ECRSH14 (accessed on 22 May 2014).

56. Donia Baldacchino, Kristina B. Torskenes, Josette Borg, Mary Kalfoss, Aaron Tonna, Clifford Debattista, Neville Decelis, and Rodianne Mifsud. "Spiritual coping of clients on rehabilitation: A comparative study between Malta and Norway (Part I)." British Journal of Nursing 22 (2013): 16-20.

57. Amanda J. Henderson, Joanna Briggs, Sue Schoonbeek, and Karen Paterson. "A framework to develop a clinical learning culture in health facilities: Ideas from the literature." International Nursing Review 58 (2011): 196-202.

58. Ann Bradshaw. "Teaching spiritual care to nurses: An alternative approach." International Journal of Palliative Nursing 3 (1997): 51-57. 
59. Josephine Attard, Donia R. Baldacchino, and Liberato Camilleri. "Nurses' and midwives' acquisition of competency in spiritual care: A focus on education." Nurse Education Today 26 (2014): 1460-66.

60. Donia R. Baldacchino. "Teaching on 'The Spiritual Dimension in Care': The perceived impact on undergraduate nursing students." Nurse Education Today 28 (2008): 501-12.

61. Patricia Benner, and Molly Sutphen. "Learning across the professions: The clergy, a case in point." Journal of Nursing Education 46 (2007): 103-08.

62. Tove Giske, and Pamela Cone. "Opening up to learning spiritual care of patients: A grounded theory study of nursing students.” Journal of Clinical Nursing 21 (2012): 2006-15.

63. Ann Purdie, Louisa Sheward, and Elaine Gifford. "Student nurse placements take a new direction." Nurse Education in Practice 8 (2008): 315-20.

64. Donia Baldacchino. "Caring in Lourdes: An innovation in students' clinical placement." British Journal of Nursing 19 (2010): 352-66.

65. Graham Gibbs. Learning by Doing: A Guide to Teaching and Learning Methods. Oxford: Oxford Polytechnic, 1988.

66. David Kolb. Experiential Learning: Experience as the Source of Learning and Development. Englewood Cliffs: Prentice-Hall, Inc., 1984.

67. Dee Marie Zyblock. "Nursing presence in contemporary nursing practice." Nursing Forum 45 (2010): 120-24.

68. Cleda Meyer. "Mentoring for spiritual caregiving: What factors enable nursing students or new graduated to provide spiritual care?" Journal of Christian Nursing 22 (2005): 38-40.

69. Barbara Pesut. "The development of nursing students' spirituality and spiritual care-giving." Nurse Education Today 22 (2002): 128-35.

70. Denise L. Mitchell, Marsha J. Bennett, and Linda Manfrin-Leder. "Spiritual development of nursing students: Developing competence to provide spiritual care to patients at the end of life." Journal of Nursing Education 45 (2006): 365-70.

71. Aru Narayanasamy. "The impact of empirical studies of spirituality and culture on nurse education." Journal of Clinical Nursing 15 (2006): 840-51.

72. Joseph D. Cortis. "Meeting the needs of minority ethnic patients." Journal of Advanced Nursing 48 (2004): 51-58.

73. Bruce D. Feldstein, Marita Grudzen, Art Johnson, and Samuel LeBaron. "Integrating Spirituality and Culture with End-of-Life Care in Medical Education." Clinical Gerontologist 31 (2008): 71-82.

74. Corinne Lemmer. "Teaching the spiritual dimension of nursing care: A survey of US baccalaureate nursing programs." Journal of Nursing Education 41 (2002): 482-90.

75. Lynn Clark Callister, Elaine A. Bond, Gerry Matsumura, and Sandra Mangum. "Threading spirituality throughout nursing education." Holistic Nursing Practice 18 (2004): 160-66.

76. Elisabeth A. Rankin, and Mary B. DeLashmutt. "Finding spirituality and nursing presence: The student's challenge." Journal of Holistic Nursing 24 (2006): 282-88.

77. Ana Maria Catanzaro, and Kathleen A. McMullen. "Increasing nursing students' spiritual sensitivity." Nurse Educator 26 (2001): 221-26. 
78. John Milliman, Andrew J. Czaplewski, and Jeffery Ferguson. "Workplace spirituality and employee work attitudes. An exploratory empirical assessment." Journal of Organisation Change Management 16 (2003): 426-47.

79. Don Grant, Kathleen O’Neil, and Laura Stephens. "Spirituality in the Workplace: New Empirical Directions in the Study of the Sacred." Sociology of Religion 65 (2004): 265-83.

80. Jamil Sadeghifar, Mohammed Bahadori, Donia Baldacchino, Mehdi Radaabadi, and Mehdi Jafari. "Relationship between Career Motivation and Perceived Spiritual Leadership in Health Professional Educators: A Correlational Study in Iran.” Global Journal of Health Science 6 (2013): 145-54.

81. John Fisher, and David Brumley. "Nurses' and carers' spiritual wellbeing in the workplace." Australian Journal of Advanced Nursing 25 (2007): 49-57.

82. Joanna Crossman. "Conceptualising spiritual leadership in secular organizational contexts and its relation to transformational, servant and environmental leadership." Leadership \& Organization Development Journal 31 (2010): 596-608.

83. Judi Neal. Handbook of Faith and Spirituality in the Workplace-Emerging Research and Practice. London: Springer, 2013, pp. 3-18.

84. Stephen G. Post, Christina M. Puchalaiski, and David Larson. "Physicians and patient spirituality: Professional Boundaries, competency and Ethics." American College of Psysicians, American Society of Internal Medicine 132 (2000): 578-83.

85. Christina M. Puchalski. "Spirituality and health: the art of compassionate medicine." Hospital Physician 37 (2001): 30-36.

86. Dee W. Ford, Lois Downey, Ruth Engelberg, Anthony L. Back, and Curtis J. Randall. "Discussing religion and spirituality is an advanced communication skill: An exploratory structural equation model of physician trainee self-ratings." Journal of Palliative Medicine 15 (2012): 63-70.

87. Michael Balboni, Adam Sullivan, Adaugo Amobi, Andrea C. Phelps, Daniel P. Gorman, Angelika Zollfrank, and John Peteet, Holly P. Briggerson, Tyler J. Vanderweele, and Tracy A. Balboni. "Why is spiritual care infrequent at the end of life? Spiritual care perceptions among patients, nurses, and physicians and the role of training." Journal of Clinical Oncology 31 (2013): 461-67.

88. Lesley W. Fry. "Towards a theory of spiritual leadership.” The Leadership Quarterly 14 (2003): 693-727.

89. Gary Geroy, Mario Fernando, and Frederick Beale. "The spiritual dimension in leadership at Dilmah Tea." Leadership \& Organization Development Journal 30 (2009): 522-39.

90. Mary Carolyn Cooper. "The intersection of technology and care in the ICU." Advances in Nursing Science 15 (1993): 23-32.

91. Louis W. Fry, Sean T. Hannah, Michael Noel, and Fred O. Walumbwa. "Impact of spiritual leadership on unit performance." The Leadership Quarterly 22 (2011): 259-70.

92. Jeanne Siddiqui. "The Therapeutic relationship in midwifery." British Journal of Midwifery 7 (1999): 111-14.

93. Agneta Schreurs. Psychotherapy and Spirituality: Integrating the Spiritual Dimension into Therapeutic Practice. London: Jessica Kingsley Publishers, 2002. 
94. Jeffery Pfeffer. Business and the Spirit. Handbook of Workplace Spirituality and Organizational Performance. New York: ME Sharpe, 2003, pp. 29-45.

95. John Arnold, Ray Randall, Joanne Silvester, Fiona Patterson, Ivan Robertson, Cary Cooper, Bernard Burnes, Don Harris, Carolyn Axtell, and Deanne Den Hartog. Work Psychology. Understanding Human Behaviour in the Workplace, 4th ed. Madrid: Pearson Education Limited, 2005.

96. William McEwan. "Spirituality in nursing." Orthopaedic Nursing 23 (2004): 321-26.

97. Afsaneh Mohammadi, Zohreh Vanaki, and Ashraf Mohammadi. "Effect of Implementation of Motivational Program Based on 'Expectancy Theory' by Head Nurses on Patients' Satisfaction." Hayat 18 (2012): 47-60.

98. Ali Khan Khuwaja, Riaz Qureshi, Marie Andrades, Zafar Fatmi, and Nadia Kha Khuwaja. "Comparison of job satisfaction and stress among male and female doctors in teaching hospitals of Karachi." Journal of Ayub Medical College, Abbottabad 16 (2003): 23-27.

99. Gilbert W. Fairholm. "Spiritual leadership: Fulfilling whole-self needs at work." Leadership \& Organization Development Journal 17 (1996):11-17.

100. Ahmed Al-Rfou, and Khalaf Trawneh. "Achieve Competitive Advantage through Job Motivation." Journal of Social Sciences 20 (2007): 105-07.

101. George Handzo, and Harold G. Koenig. "Spiritual Care: Whose job is it anyway?" Southern Medical Journal 97 (2004): 1242-44.

102. Christopher Levison. "Partners in care." Nursing Management 12 (2005): 18-21.

103. Rene van Leeuwen, Lucas Tiesinga, Doeke Post, and Henk Jochemsen. "Spiritual care: Implications for nurses' professional responsibility." Journal of Clinical Nursing 15 (2006): 875-84.

104. Cynthia Johnston, and Ann E. Mohide. "Addressing diversity in clinical nursing education: Support for preceptors." Nurse Education in Practice 9 (2009): 340-47.

105. Jason Azzopardi. “The sacredness of patient care.” Il-Mument 3 (2010): 13-15.

106. Linda Ross. "Spiritual care in nursing: An overview of the research to date." Journal of Clinical Nursing 15 (2006): 852-62.

107. Neil Cockell, and Wilfred McSherry. "Spiritual care in nursing: An overview of published international research.” Journal of Nursing Management 20 (2012): 958-69.

(C) 2015 by the author; licensee MDPI, Basel, Switzerland. This article is an open access article distributed under the terms and conditions of the Creative Commons Attribution license (http://creativecommons.org/licenses/by/4.0/). 